\title{
Dürtüsellik ile Sosyal Medya Aşerme Arasındaki İlişkide FOMO'nun Aracılık Etkisi
}

\author{
DOI: $10.26466 /$ opus.648795 \\ *
}

\section{Mustafa Ercengiz *}

* Dr.Öğr.Üyesi, Ağrı İbrahim Çeçen Üniversitesi Eğitim Fakültesi Eğitim Bilimleri Bölümü, Rehberlik Ve Psikolojik Danışmanlık Ana Bilim Dalı E-Posta: mercengiz@agri.edu.tr

ORCID: 0000-0002-6891-8462

\section{Öz}

Bu çalışmada aracılık etkisi test edilmiştir. Dürtüsellik ile Sosyal Medya Aşerme arasındaki ilişkide FOMO'nun aracıllk etkisi test edilmiştir. Araştırmanın katılımoı grubunu 106'sl (\%42.2) kadın, 145'i (\%57.78) .erkek olmak üzere toplam 251 birey oluşturmaktadır. Araştırmada Barratt Dürtüsellik Ölçeği, Sosyal Medya Aşerme Ölçeği ve Sosyal Ortamlarda Gelişmeleri Kaçırma Korkusu Ölçeği kullanılmıştır. Arabuluculuk analizi, Hayes'in (2017) süreç uygulaması kullanılarak yapılmıştır. Dürtüselliğin FOMO'yu yordama gücü incelenmiş ve Dürtüselliğin FOMO'yu anlaml bir şekilde yordadiğı $(F=12.99, R 2=.05, p<.0001)$ belirlenmiştir. Dürtüselliğin, FOMO içindeki toplam varyansın\% 5'ini açıklamaktadır. 2. modelde geçildiğinde Dürtüselliğin Sosyal Medya Aşermeyi yordama gücü incelenmiş ve sonuç anlamlı $(F=7.41, R 2=.03, p<.0001)$ olarak belirlenmiştir. 3. Modelde Dürtüsellik ve Sosyal Medya Aşerme arasındaki ilişkide FOMO'nun aracılık etkisi incelenmiş ve FOMO'nun tam aracılık etkisi gösterdiğgi $(F=22.19, R 2=.15, p<.0001)$ belirlenmiştir. Dürtüselliğin Sosyal Medya Aşermeyi yordama gücü toplam varyansta \% 3 iken FOMO'nun analize dahil edilmesiyle varyans \%15'e kadar çıkmıştır. Dolaylı etkinin anlamlı olup olmadığının anlaşılması için Sobel ve Bootstrapping Testi uygulanmış sonuçlar istatistiksel (Sobel $Z=-4.62, p<.0001$ ) olarak anlamlı olduğu belirlenmiştir.

Anahtar Kelimeler: Dürtüsellik, Aşerme, FOMO 


\title{
Mediator Effect of FOMO in the Relationship Between Impulsivity and Social Media Craving
}

\begin{abstract}
In this study, the mediating effect was tested. The mediator effect of FOMO was tested in the relationship between impulsivity and social media craving. The participants of the study consisted of 251 individuals, 106 of whom were females and 145 of whom were males. Barratt Impulsivity Scale, Social Media Craving Scale and fear of missing out Scala were used in the study. Mediation analysis were performed using Hayes' (2017) process application. The power of impulsivity to interpret FOMO has been studied and it has been determined that impulsivity predicts FOMO in a meaningful way ( $F=12.99, R 2=.05$, $p<.0001)$. Impulsivity explains $5 \%$ of the total variance in FOMO. 2 nd ed. when the model was passed, the power of impulsivity to process Social Media craving was examined and the result was determined as significant. ( $F=7.41, R 2=.03, p<.0001)$. 3. In the model, the mediated effect of FOMO in the relationship between impulsivity and social media craving was examined and it was determined that FOMO showed a full mediated effect $(F=22.19, R 2=.15, p<.0001)$. The power of impulsivity to predict social media craving was $3 \%$ in the total variant, while the variance was up to $15 \%$ with the inclusion of FOMO in the analysis. The results of Sobel and Bootstrapping tests were determined to be statistically significant in order to determine whether the indirect effect was significant (Sobel $Z=-4.62, p<.0001$ ).
\end{abstract}

Keywords: impulsivity, Craving, FOMO 


\section{Giriş}

Son çeyrek yüzyılda İnternet ve ilgili teknoloji (akıllı telefonlar, mobil sosyal medya vb.) kullanımında dikkat çekici yükselmeler olduğu görülmektedir. We are Social küresel teknoloji araştırmaları 2019 rapor sonucuna göre 2018 Ocak ayına nispeten 2019 Ocak ayında internet kullanıcılarında \%9'luk bir artış gerçekleşmiş ve internet kullanıcılarının sayısı 3 milyar 660 milyon bireyden 4 milyar 390 milyon bireye ulaşmıştır. Diğer bir ifadeyle bir yıllık gibi bir zaman diliminde yaklaşı 730 milyon bireyin interneti ilk defa kullanmaya başladığı söylenebilir. Worldometers verilerine göre, güncel Dünya nüfusunun 7 milyar 741 milyon kişi olduğu bağlamında değerlendirildiğinde yıllık 730 milyon bireyin internet kullanımına dâhil olması oldukça yüksek sayılabilecek bir oran olduğu söylenebilir. We are Social 2019 Türkiye raporunda 2018 Ocak verilerine göre 54.33 milyon internet kullanıcı varken 2019 Ocak ayında bu sayı 59.36 milyon kullanıcıya çıkmıştır. Türkiye İstatistik Kurumu'nun 2018 yılı verilerine göre; hanelerde internet erişim oranı \% 83, $8^{\prime}$ ken işletmelerde internet erişim oranı \% 95,3 seviyelerine ulaşmış durumdadır (TÜIK, 2019). Nitekim Worldometers verilerine göre bir yılda basılan kitap sayısı 2 milyon 249 bin adet iken yalnızca bir günde satılan cep telefonu sayısı 5 milyon civarında. Yukarıda belirtilen veriler bağlamında teknoloji kullanımındaki baş döndürücü artışın sonuçlarının kestirilmesinin önemli bir problem alanı olarak karşımızda durduğu söylenebilir.

Yaygınlık oran hızla ilerleyen internet ve ilgili teknolojilerin insanoğlunun yaşamına önemli kolaylıklar (internet bankacılığı, mobil bankacılık, internette alışveriş vb.) sağlamasının yanında çeşitli problem alanlarının oluşumunu (Darcin ve diğ., 2016; Lopez-Fernandez, 2017) beraberinde getirmektedir. FOMO [Fear of Missing Out (Gelişmeleri Kaçırma Korkusu)] ve Sosyal Medya Aşerme, internet ve ilgili teknoloji kullanımının getirdiği problemler arasında güncel kavramlar arasında sayılabilir.

\section{FOMO ve Dürtüsellik}

Son zamanlarda araştırmalara konu olan Fear Of Missing Out (Gelişmeleri Kaçırma Korkusu) ifadesinin baş harflerinin kodlanmasıyla kavramsallaştırılan FOMO önemli bir problem alanıdır (Gil, Chammarro ve Oberst, 2015). 
FOMO, Przybylski ve diğerleri (2013) tarafından " Diğer İnsanlar Sizsiz Ĕ̆leniyor" korkusu olarak tanımlanmıştır. Ayrıca FOMO, bireylerin sosyal ağlarda ödüllendirici yaşantılar edinebilmelerinin oluşturdu yaygın kaygı olarak da tanımlanabilmektedir (Dossey, 2014; Przybylski ve diğ., 2013). FOMO'nun diğerlerinin yaptıklarıyla sürekli bağlantıda kalma arzusuyla karakterize olduğu belirtilmiştir (Przybylski ve diğ., 2013). Sürekli bağlantı kurma arzusuyla karakterize olan Z kuşağı neslinin sosyal ağlarını her türlü gelişme için sürekli olarak kullanmasına neden olmuştur (David, Roberts ve Christenson, 2017). Yanı sira Holt-Lunstad, Smith ve Layton (2010) FOMO'nun yayılımındaki nedeni güçlü sosyal medya ağlarına sahip olma, bireylerin daha mutlu ve eğlenceli bir yaşam sürme ihtimallerini arttırması olduğunu belirtmişlerdir.

Araştırmanın diğer bir değişkeni olan Dürtüsellik, nörofizyolojik olarak bireyin sergilediği davranışlarda bağlam ve sonuçların uyumsuzluğu olarak değerlendirilmektedir (Barratt ve Patton, 1983). Ayrıca dürtüsellik, sergilenen davranışın olumsuz sonuçlarına duyarsızlaşma, bilginin işlenmesinin beklenilmeksizin tepki verilmesi olarak tanımlanmaktadır (Moeller, Barratt, Dougherty ve Schmýtz, 2001; Evenden, 1999).

Dürtüsellik, davranışsal yönden incelendiğinde yapılan eylemin sonucu bakımından oldukça kötü sonuçlar doğurmasına rağmen davranışın tekrar edilmesi olarak ifade edilmektedir (Evenden, 1999). Dürtüselliğin dikkatsizlik, risk alma, heyecan ve haz arama gibi dışa dönük davranış örüntüleriyle karakterize olduğu söylenebilir (Hollander ve Evers, 2001).

Dürtüsellik, tek başına karakterize olan bir bozukluk olmamakla birlikte bipolar bozukluğu, hiperaktivite ve trikotilomani gibi bozukluklara eşlik edebilir (Chamberlain ve Sahakian 2007; Evenden 1999). Yanı sıra dürtüsellik maddenin kötüye kullanımı, intihar ve davranışsal bağımlılıklar gibi problemlere de yol açabilmektedir (Swann, Moeller, Steinberg, Schneider, Barratt ve Dougherty, 2007). Yapılan araştırma sonuçlarına göre internet bağımlılığı ve akıllı telefon bağımlılığı ile dürtüsellik arasından pozitif korelasyonların olduğu belirtilmiştir. (Dalbudak, Evren, Topçu, Aldemir, Coşkun, Bozkurt, Evren ve Canbal, 2013; Kim ve diğ., 2014; Mazhari, 2012; Ko, Yen, Yen, Chen ve Chen, 2012). Dürtüsellik ve sosyal medya bağımlılığı arasındaki ilişkiler (Kim ve diğ., 2014; Mazhari, 2012; Ko, Yen, Yen, Chen, ve Chen, 2012; Dalbudak, Evren, Topçu, Aldemir, Coşkun, Bozkurt, Evren ve Canbal, 2013) 
ve sosyal medya bağımlılı̆̆ı ve FOMO arasındaki ilişki bağlamında düşünüldüğünde dürtüsellik ve FOMO arasında ilişkinin olabileceği tahmin edilmektedir. Çınar ve Mutlu (2018) tarafından yapılan çalışma kapsamında FOMO ile Dürtüsellik arasında pozitif yönde korelasyon olduğunun belirlenmesi de bağlamsal çalışmalar neticesiyle yapılan çıkarımı desteklemektedir.

\section{Sosyal Medya Aşerme, FOMO ve Dürtüsellik}

İnternetin yaygınlaşmasıyla beraber yaygınlaşan sosyal medya bağımlılı̆̆ı, son yıllarda önemli bir araştırma alanı olarak birçok çalışmaya konu olmuştur (Arısoy, 2009). Sosyal medya bağımlılı̆̆ı alan yazında çok farklı şekillerde tanımlanabilmektedir. Sosyal medyaya önlenemez bağlanma isteği, sosyal medyanın kullanımının durdurulamaması ve sosyal medyaya bağlanılamadığı anlarda kaygı duygusu ve tepkisellik yaşanması sosyal medya bağımlılı̆̆ı olarak tanımlanabilir (Griffiths ve diğ., 2014; Savcı ve Aysan, 2018). Alexa.com verilerine göre "INSTAGRAM'da" 3 aylık verilere göre günlük 7.18 dakika harcanırken kullanıcı başına günlük 6.870 hesap görüntülemesi yapılmaktadır ve 120 milyonun üzerinde fotoğraf paylaşımı yapılırken 4 milyarın üzerinde beğeni yapılıyor. Yalnızca bir sosyal medya ağı olan "INSTAGRAM'da" çok yoğun bir paylaşım ve beğeni trafiğinin yaşanmasının sebebi nedir? Savcı ve Aysan'a (2018) göre sosyal medyanın insanların kısa bir süre içerisinde beğenildiği, onaylandığı ve kabul edildiğ $i$ platform olması nedeniyle kullanım yaygınlığının arttığı söylenebilir. Beğenilme arzusunun bireyler için önemli olması (Taaylor-Horzum, 2015) bağlamında düşünüldüğünde yukarıda Savcı ve Aysan (2018) tarafından belirtilen cevabın tatmin edici olduğu söylenebilir. Bu bağlamda sorunlu sosyal medya kullanımı olmasa bile, sosyal medyayı kullanma arzusu ve isteği, bu sosyal işlevlerin (insanların kısa bir süre içerisinde beğenildiği, onaylandığı ve kabul edilmesi) bir sonucu olarak ortaya çıkabilir (Savcı ve Griffiths, 2019). Sosyal medya bağımlılığının ortaya çıkardığı sosyal medyayı kullanma isteği sosyal medya aşermesi olarak kavramsallaştırılmıştır (Hormes, Kearns ve Timko, 2014).

Oxford sözlüğünde "a strong desire" olarak ifade edilen "Carving" kavramı Türkçe 'de Aşerme olarak kullanılmıştır (Şengül ve Dilbaz, 2013). Aşerme kavramı son yıllarda davranışsal bağımlılık için kullanılmaya başla- 
narak (Grant, Potenza, Weinstein ve Gorelick, 2010) bağımlılık nörobiyolojisinin tanımlanmasında kullanılan 3'lü grup (Beyin ödül sistemi, maddenin pekiştirici etkisi ve Aşerme) arasında değerlendirilmeye başlanmıştır (Koob ve Volkow, 2010).

Caselli ve Spada, (2010) bireylerde alkol yoksunluğu, nikotin bağımlılığ1 ve problemli kumar oynama süreçlerinde aşermenin aktif bir süreç olarak işlediğini belirtimiştir. Yine benzer araştırma sonuçlarına göre sigara içme ve alkol bağımlılığında aşermenin yordayıcı rol üstlendiği belirlenmiştir (Caselli, Nikcevic, Fiore, Mezzaluna ve Spada, 2012; Caselli ve Spada, 2011). Aşermenin, Sosyal medya bağımlılı̆̆ (Turel ve Bechara, 2016) ve internette oyun oynama bozukluğu (Dong, Wang, Du ve Potenza, 2017) ile ilişkili olduğu belirlenmiştir. Dolayısıyla aşermenin internet ve ilgili teknolojiler ile ilişkili olduğu söylenebilir. Bu bağlamda aşermenin sosyal medya boyutunun anlaşılması için Savcı ve Griffiths (2019) Sosyal Medya Aşerme Ölçeği ve Wegmann, Stodt ve Brand, (2015) tarafından uyarlama çalışması yapılan İnternet Bağımlılığı Ölçeğinin alt boyutlarından biri olarak Sosyal Medya Aşerme ölçeği geliştirilmiştir.

FOMO, Özerk Benlik Teorisi'ne göre açıklanmaktadır (Ryan ve Deci, 2000). Bu teoriye göre bireylerin kendilerini iyi hissedebilmeleri için başkaları tarafından beğenilme, tatmin edici ve destekleyici sosyal ilişkilere sahip olmanın zorunluluğuna dikkat çekilmektedir (Gagne ve Deci, 2005; Riordan, Flett, Hunter, Scarf ve Conner, 2015). Dolayısıyla psikolojik ihtiyaçlardaki artış ile FOMO arasında pozitif ilişkinin olduğu söylenebilir (Vega, Munoz ve Garcia, 2019). FOMO yaşayan bireylerin sosyal ağları kullanmaya dönük yüksek anksiyete yaşadıkları rapor edilmiştir (Oberst, Wegmann, Stodt, Brand ve Chamarro, 2017).

FOMO yaşayan bireylerin iletişim aracı olarak reel iletişim yerine sosyal medya ağlarını kullandıkları belirtilmiştir (Dossey, 2014). Yanı sıra FOMO ile sosyal medya bağımlılı̆̆ı arasında ilişki olduğu raporlanmıştır (Beyens, Frison ve Eggermont, 2016 ; Oberst ve diğ., 2017). Yanı sıra FOMO'nun sosyal medyanın yoğun kullanımına neden olduğu (Wang, Zhang, Chen ve Zeng, 2018); FOMO'nun ait olma ihtiyaciyla Facebook kullanma yoğunluğu arasındaki ilişkide aracı rol üstlendiği görülmektedir (Beyens, Frison ve Eggermont, 2016).

FOMO ile Sosyal medya Bağımlılığı arasındaki anlamlı ilişkiler (Beyens, Frison ve Eggermont, 2016; Oberst ve diğ., 2017) ve Sosyal medya aşerme ile 
sosyal medya bağımlılığı arasındaki anlamlı ilişki (Turel ve Bechara, 2016) göz önünde bulundurulduğunda FOMO ile Sosyal Medya Aşerme arasında anlamlı ilişkilerinin olabileceği tahmin edilmektedir.

Bağımlılıkla ilişkili kavramlar açısından tanılaması en zor kavramlardan biri olan Aşerme (craving) Dürtü kuramı ile etkili şekilde açılanmaktadır. Buna göre Aşerme, bireyin yeni denge durumuna erişebilmesi için gerekli davranışı sergileme dürtüsü olarak ele alınır (Barlas, 2018). Bağımlılık tedavisinin sonlanmasıyla birlikte dürtüselliğin maddenin tekrar kullanımına neden olması Aşerme kavramı çerçevesinde ele alınmaktadır (Pattij ve De Vries, 2013). Yanı sıra bağımlılıkla ilgili fizyolojik sürecin sonlanmasından sonra maddenin yeniden deneyimlenmesi için yaşanan aşerme durumunda dürtüsellik düzeyinin yükseldiği gözlemlenmiştir (Pattij ve De Vries, 2013; Shaham, Erb ve Stewart 2000).

Yapılan alan yazın incelemeleri araştırma değişkenlerinden olan Dürtüsellik, FOMO ve Sosyal Medya Aşermenin ilgili makaleler düzeyinde yapılan incelemelerde ilişkili kavramlar olabileceğini göstermektedir. Nitekim araştırmaya konu olan kavramların bir bütün halinde incelendiği herhangi bir çalışmaya rastlanmamıştır. Dolayısıyla alan yazında bu anlamda bir boşluk olduğu söylenebilir. Fakat çalışmanın nihai amacı yukarıda verilen internet ve ilgili teknolojilerin kullanımı ve ilgili bozuklukların artışındaki yüksek oranların önlenmesi için ne yapılabilir sorusuna cevap aranmasıdır. Yapılan çalışma ile internet ve ilgili teknolojilerin kullanımı neticesiyle ortaya çıkan problemlerin etiyolojisinin anlaşılması için veri birikiminin oluşumunun sağlanarak teknolojiye ilişkin problemlerin sağaltımına yönelik geliştirilecek müdahale yöntemlerine kaynak sağlanması amaçlanmıştır.

\section{Yöntem}

\section{Çalışma Grubu}

Çalışmanın katılımcı grubunu, 2018-2019 güz döneminde Ağrı İbrahim Çeçen Üniversitesinde eğitim gören 106'sı kadın, 145'i erkek olmak üzere toplam 251 birey oluşturmaktadır. Katılımcıların belirlenmesinde uygun örneklem yöntemi kullanılmıştır. Uygun örnekleme yöntemi, zaman, para ve emek açısından var olan sınırlamalar nedeniyle örnekleme kolay erişilebilir ve uygulanabilir birimlerden seçilmesidir. (Büyüköztürk ve diğ., 2008). 
Veri toplama araçları araştırmaya gönüllü katılım sağlayan üniversite eğitim gördükleri sınıflarda uygulanmıştır.

\section{Veri Toplama Araçları}

Barratt Dürtüsellik Ölçeği Kısa Formu (BIS-11-KF): Tamam, Güleç ve Karaman (2013) tarafından Türkçe uyarlaması yapılan ölçek 15 Maddeli 4'lü likert yapıdadır. Ölçek; "Plan Yapmama, Dikkat Dürtüselliği ve Motor dürtüsellik" olmak üzere 3 alt boyuttan oluşmaktadır. Ölçeğin toplam iç tutarlılık düzeyi 0,82 düzeyindedir. Ölçekten alınan yüksek puanlar yüksek dürtüselliğe işaret etmektedir.

Sosyal Medya Aşerme Ölçeği (SMAÖ): Savcı ve Griffiths (2019) tarafindan Penn Alkol Aşerme Ölçeğinin (Flannery, Volpicelli ve Pettinati, 1999) değiştirilmesi ile geliştirilen SMAÖ 5 madde tek alt boyuttan oluşmaktadır. Açklayıcı Faktör Analizi (AFA) sonucunda, SMAÖ'nin toplam varyansın\% 55,75'ini açklayan bir boyuttan oluştuğu görülmüştür. Bu tek boyutlu yap1 Doğrulayıc Faktör Analizi (DFA) ile iki farklı örnekte test edilmiştir. DFA sonucunda SMCS'nin kabul edilebilir uygun endeks değerlerine sahip olduğu belirlenmiştir. SMCS'nin güvenilirliği, Cronbach $\alpha$ iç tutarlılık katsayısı, düzeltilmiş madde-toplam korelasyon katsayıları ve test-tekrar test yöntemi ile değerlendirilmiş ve Ölçeğin kullanılabilir değerlerde olduğu görülmüştür (Savc1 ve Griffiths, 2019).

Sosyal Ortamlarda Gelişmeleri Kaçırma Korkusu Ölçeği(SGKKÖ): Gökler, Aydın, Ünal ve Metintaş, (2016) tarafından geçerlik ve güvenirlik çalışması yapılan Sosyal Ortamlarda Gelişmeleri Kaçrıma Korkusu Ölçeği (SGKKÖ) 10 madde tek alt boyuttan oluşan 5'li likert yapıdadır. Ölçek maddeleri 1= "hiç doğru değildir" ile $5=$ "aşırı şekilde doğrudur" arasında puanlanmaktadır. Ölçekten en az 10 en fazla 50 puan alınabilir. Alınan yüksek puanlar bireyin FOMO düzeyinin yüksekliğine işaret ederken alınan düşük puan FOMO düzeyinin düşük olduğunu gösterir. Ölçeğin Cronbach's Alpha katsayısı .81 olarak belirlenmiştir. Ölçeğin faktör yükleri 0.36-0.77 arasında değişmekte ve test-tekrar test güvenilirlik katsayısı $=0.8^{\prime}$ dir. 


\section{İşlem}

Ölçme araçlarının uygulanması sırasında, gönüllü̈lük ilkesinin olduğu ve soruları cevaplamak istemeyenler için bir zorunluluk olmadığı belirtilmiştir. Katılımclar tarafından Ölçme araçlarının cevaplama süresi 20 ile 25 dakika aralığında sürmüştür. Ölçeklerdeki soruların cevaplanması esnasında oluşabilecek güven problemlerinin engellenmesi için kişisel bilgilerin ölçek bataryalarına yazılmaması istenmiştir. Uygulamada eksik ve hatalı oldukları belirlenen 5 anket analize dâhil edilmemiştir. Araştırmadan elde edilen verilerin analizleri istatiksel paket programı aracilı̆̆ıla yapılmıştır. Araştırmada Pearson Momentler Çarpımı Korelasyon Analizi ve Basit Doğrusal Regresyon analizleri kullanılmıştır. Analizlere başlanılmadan önce analizleri gerçekleştirmek için gerekli varsayımlar test edilmiştir. Bu bağlamda veri setinin basıklık-çarpıklık değerlerine bakılmış ve parametrik testlerin ön koşullarından olan normallik ve lineer ilişki sayıltılarının karşılandığı belirlenmiştir. Yanı sıra değişkenler arasında ilişki düzeyinin yüksek olmadığı belirlenmiştir. Çoklu bağlantı sorununun olmadığının anlaşılması amacıyla Tolerans, VIF ve CI değerleri incelenmiştir. Tolerans değeri 0,10 'da küçük olmalıyken, VIF değeri 10 'dan küçük olmalı aynı zamanda CI değeri ise 10-30 değerleri arasında olmalıdır (Albayrak, 2005). Yapılan çalışma sonucunda çoklu bağlantı problemi belirlenmemiştir. Uç değerleri belirlemek amacıyla Mahalanobis uzaklık değerleri incelenmiş ve veri setinden 8 katılımcıdan elde edilen verilen aykırı değerlere sahip olduğu belirlenmiştir. Belirlenen veriler analiz kapsamına alınmayarak analiz işlemi 246 veri üzerinden gerçekleştirilmiştir.

\section{Araştırmanın Modeli}

Bu çalışmada Dürtüsellik ve Sosyal Medya Aşerme arasındaki ilişkide FOMO'nun aracılık etkisi incelenmiştir. Analizden önce, aracılık analizleri için ön koşullar incelenmiştir. Buna göre, veriler tek ve çoklu normallik sağlamalıdır. Yanı sıra, veri setinde çoklu bağlantı problemleri olmamalıdır (Çokluk, Sekercioğlu ve Büyüköztürk, 2012). 
Çokluk, Sekercioğlu ve Büyüköztürk' e (2012) göre değişkenler arasındaki ikili korelasyonlar .90 'dan büyük olduğunda, çoklu doğrusallık problemleri ortaya çıkar. İlk olarak, çarpıklık ve basıklık katsayıları dikkate alınarak, veri seti tek değişkenli normallik açısından incelenmiştir. Çarpıklık ve basıklık değerleri + 1 ile -1 arasında olmalıdır (Çokluk ve diğ., 2012). Çoklu normallik analizinin yapılması için matris diyagramı incelenmiş ve matris diyagramının eliptik bir yapı sergilediği görülmüştür. Çokluk ve diğerleri 'ne (2012) göre matris diyagramının eliptik dağılımı veri setinde çoklu normalliğin olduğunu göstermektedir. Ön koşullar sağlandıktan sonra Process programında model 4 kullanılarak aracılık etkisi incelenmiştir.

\section{Bulgular}

Tablo 1. Betimleyici istatistikler ve korelasyonlar

\begin{tabular}{llll}
\hline & 1 & 2 & 3 \\
\hline 1. Sosyal Medya Aşerme & - & & \\
2. FOMO & $.39^{* *}$ & - & \\
3. Dürtüsellik & $.17^{* *}$ & $.23^{* *}$ & - \\
X & 11.45 & 24.61 & 27.83 \\
ss & .31 & 7.19 & 6.57 \\
Skewness & .215 & .353 & .776 \\
Kurtosis & -.413 & .037 & 1.516 \\
\hline
\end{tabular}

$p<.01$ ** ve $N=251$

Tablo 1, bu çalışmada tüm ana değişkenler arasındaki korelasyonları, basıklık-çarpıklık, standart sapma ve ortalama değerler verilmiştir. İki değişkenli korelasyonlar tüm değişkenlerin orta derecede birbirleriyle ilişkili olduğunu göstermiştir. Elde edilen verilerin parametrik bir dağılımı olup olmadığını belirlemek için çarpıklık ve basıklık değerleri incelenmiş olup belirtilen değerler -1 ile 1 arasında olduğu için parametrik dağılım gösterdiği belirlenmiştir (Büyüköztürk, 2010). 
Tablo 2. Dürtüsellik ile Sosyal Medya Aşerme arasındaki ilişkide FOMO'nun aracılık etkisine ilişkin sonuçlar

\begin{tabular}{|c|c|c|c|c|c|c|c|}
\hline \multicolumn{8}{|c|}{ BAĞIMLI DEĞİŞKEN : FOMO } \\
\hline \multirow[t]{2}{*}{ MODEL ÇIKTISI } & $\mathrm{R}$ & $\mathrm{R} 2$ & MSE & $\mathrm{F}$ & df1 & df2 & $\mathrm{p}$ \\
\hline & .22 & .05 & 49.30 & 12.99 & 1 & 244 & $<.001$ \\
\hline 1. Model & \multicolumn{2}{|c|}{ Katsayı } & SE & $\mathrm{t}$ & $\mathrm{p}$ & LLCI & ULCI \\
\hline Sabit Değer & \multicolumn{2}{|c|}{17.76} & 1.95 & 9.11 & $<.001$ & 13.922 & 21.606 \\
\hline Dürtüsellik & \multicolumn{2}{|c|}{.25} & .07 & 3.60 & $<.001$ & .11 & .38 \\
\hline \multicolumn{8}{|c|}{ BAĞIMLI DEĞİŞKEN : Sosyal Medya Aşerme } \\
\hline \multirow[t]{2}{*}{ MODEL ÇIKTISI } & $\mathrm{R}$ & $\mathrm{R} 2$ & MSE & $\mathrm{F}$ & df1 & df2 & $\mathrm{p}$ \\
\hline & .17 & .03 & 22.60 & 7.41 & 1 & 244 & $<.001$ \\
\hline 2. Model & \multicolumn{2}{|c|}{ Katsayı } & se & $\mathrm{t}$ & $\mathrm{p}$ & LLCI & ULCI \\
\hline Sabit Değer & \multicolumn{2}{|c|}{7.95} & 1.32 & 6.02 & $<.001$ & 5.35 & 10.55 \\
\hline Dürtüsellik & \multicolumn{2}{|c|}{.13} & .05 & -2.72 & $<.001$ & 0.4 & .22 \\
\hline \multicolumn{8}{|c|}{ BAĞIMLI DEĞİŞKEN : Sosyal Medya Aşerme } \\
\hline \multirow[t]{2}{*}{ MODEL ÇIKTISI } & $\mathrm{R}$ & $\mathrm{R} 2$ & MSE & $\mathrm{F}$ & df1 & df2 & $\mathrm{p}$ \\
\hline & .39 & .15 & 19.77 & 22.19 & 2 & 243 & $<.001$ \\
\hline 3. Model & \multicolumn{2}{|c|}{ Katsayı } & SE & $\mathrm{t}$ & $\mathrm{p}$ & LLCI & ULCI \\
\hline Sabit Değer & \multicolumn{2}{|c|}{3.63} & 1.43 & 2.54 & $<.001$ & .82 & 6.45 \\
\hline FOMO & \multicolumn{2}{|c|}{.24} & .04 & 5,99 & $<.001$ & .16 & .32 \\
\hline Dürtüsellik & \multicolumn{2}{|l|}{.07} & .04 & 1.49 & $.05<$ & -.02 & .15 \\
\hline
\end{tabular}

İlk olarak 1. modelde dürtüselliğin FOMO'yu yordama gücü incelenmiş ve Dürtüselliğin FOMO'yu anlamlı bir şekilde yordadığı ( $\mathrm{F}=12.99, \mathrm{R} 2=.05$, $\mathrm{p}<.0001$ ) belirlenmiştir. Dürtüselliğin, FOMO içindeki toplam varyansın \% 5'ini açıklamaktadır. 2. modele geçildiğinde Dürtüselliğin Sosyal Medya Aşermeyi yordama gücü incelenmiş ve sonuç anlamlı ( $\mathrm{F}=7.41, \mathrm{R} 2=.03, \mathrm{p}<.0001)$ olarak belirlenmiştir. 3. Modelde Dürtüsellik ve Sosyal Medya Aşerme arasındaki ilişkide FOMO'nun aracılık etkisi incelenmiş ve FOMO için önerilen Yapısal Eşitlik Modelinin (YEM) anlamlı olduğu (F=22.19, R2=.15, p<.0001) belirlenmiştir. Dürtüselliğin Sosyal Medya Aşermeyi yordama gücü toplam varyansta \% 3 iken FOMO'nun analize dahil edilmesiyle varyans \%15'e kadar çıkmıştır. Dolayısıyla Dürtüsellik ve Sosyal medya Aşerme arasındaki ilişkide FOMO'nun aracılık etkisi olduğu söylenebilir.

Tablo 3. Arabuluculuk etkisinin önemi ilişkin sonuç

\begin{tabular}{lllll}
\hline \multirow{2}{*}{ FOMO } & ETKİ & Boot SE & BootLLCI & BootULCI \\
\cline { 2 - 5 } & .06 & .02 & .03 & .10 \\
\hline Dolaylı Etki için Normallik Testi & ETKİ & Se & $\mathrm{Z}$ & $\mathrm{p}$ \\
\cline { 2 - 5 } & -.25 & .05 & -4.62 & $<.001$ \\
\hline
\end{tabular}


Dolaylı etkinin anlamlı olup olmadığının anlaşılması için Sobel ve Bootstrapping Testi uygulanmış sonuçlar istatistiksel (Sobel $Z=-4.62$, $\mathrm{p}<.0001$ ) olarak anlamlı olduğu belirlenmiştir.

\section{Tartışma}

Çalışma kapsamında ilk olarak, Dürtüsellik ve Sosyal Medya Aşerme arasındaki ilişkide FOMO'nun aracılık etkisi test edilmiştir. Bulgular FOMO'nun Dürtüsellik ile Sosyal Medya Aşerme arasındaki ilişkide aracılık ettiğini göstermiştir. Yapılan çalışmada teorik temele dayanarak önerilen regresyon modellerinin uygun olduğu ve FOMO'nun aracılık ettiği belirlenmiştir.

Yapılan çalışmada edinilen bulguların karşılaştırılabileceği herhangi bir bulguya rastlanılmamıştır. Nitekim çalışmanın değişkenlerinden olan dürtüsellik ile sosyal medya bağımlılı̆̆ (Kim ve diğ., 2014; Mazhari, 2012; Ko, Yen, Yen, Chen ve Chen, 2012; Dalbudak, Evren, Topçu, Aldemir, Coşkun, Bozkurt, Evren ve Canbal, 2013) ve sosyal medya bağımlılığı ile sosyal medya aşerme arasındaki pozitif korelasyonlar (Turel ve Bechara, 2016) bağlamında düşünüldügünde dürtüsellik ile sosyal medya aşerme arasında anlamlı düzeyde ilişkilerinin olabileceği söylenebilir. Dolayısıyla araştırma kapsamında Dürtüsellik ve Sosyal Medya Aşerme değişkenleri arasındaki anlamlı düzeyde ilişkinin alan yazın verilerini desteklediği söylenebilir. Yanı sıra Aşerme, genel olarak bağımllıkla ilgili fizyolojik sürecin sona ermesinden sonra gösterilen dengeleme dürtüsü olarak ele alınmaktadır (Barlas, 2018). Aşerme durumunun yaşandığı durumlarda dürtüsellik oranın da arttığ (Pattij ve De Vries, 2013; Shaham ve diğ., 2000) düşünüldüğünde aşerme ve dürtüsellik arasında pozitif korelasyonlar olduğu söylenebilir. Diğer bir anlatımla iki değişkenin birbirlerinin yordayıcısı olduğu sonucuna varılabilir. Dolayısıyla araştırma kapsamında edinilen bulguların alan yazın verilerini desteklediği söylenebilir.

Dürtüselik ve Aşerme arasındaki anlamlı ilişkinin sebebi nedir? Dürtüsellik ve Aşerme kavramlarının bir arada çalışıldığı çalışmalar oldukça azdır (Pattij ve De Vries, 2013; Shaham, Erb ve Stewart 2000). Nitekim dürtüsellikbağımlılık ve bağımlılık-aşerme arasındaki ilişkinin boyutu anlaşılmasının Dürtüsellik-Aşerme arasındaki ilişkinin nedenselliğiyle ilgili bilgi verebileceği düşünülebilir. 
İçe dönük kişilik yapısındaki bireylerin sosyal denge kurmak için dışa dönük kişilik yapısındaki bireylerin sosyal medyayı sosyal gelişim (arkadaşlık ilişkileri vb.) için kullandıkları düşünülmektedir (Kuss ve Griffiths, 2011). Sosyal Medya Bağımlılığı ve kişilik özelliklerinin incelendiği çalışmalarda dışa dönük kişilik özelliklerine sahip bireylerin Sosyal Medya Bağımlısı olma oranlarının içedönük kişilik özelliğine sahip bireylere göre daha yüksek olduğu söylenebilir (Wilson, Fornasier ve White, 2010). Yanı sıra dürtüsel bireylerin daha çok dışadönük kişilik yapısına sahip oldukları belirtilmiştir (Yazıcı ve Yazıcı, 2010; Güleç ve diğ., 2009). Dolayısıyla Dürtüsellik ve Sosyal Medya Bağımlığında dışa dönük kişilik yapısının ortak payda olarak ilişkili olduğu söylenebilir. Yanı sıra Sosyal medya bağımlılı̆̆1 ve Sosyal medya aşerme arasındaki anlamlı düzeyde korelasyonlar (Turel ve Bechara, 2016) ve genel olarak değişkenler arasındaki ortak yapıların korelasyon değerlerini yükseltebileceği düşünüldügün̈de araştırma kapsamında edinilen Dürtüsellik ve Sosyal medya aşerme arasındaki anlamlı ilişkinin nedenselliği üzerine fikir oluşturabileceği söylenebilir.

Araştırmanın diğer bir çıtısına göre Dürtüsellik FOMO'yu anlamlı olarak yordamaktadır. Alan yazın incelendiğinde Dürtüsellik ve FOMO değişkenlerinin birlikte incelendiği çok sınırlı sayıda çalışmaya rastlanılmıştır (Çınar ve Mutlu, 2018). Dolayısıyla araştırma sonuçlarının karşılaştırılabileceği sınırlı veri birikimi bulunmaktadır. Çınar ve Mutlu (2018) Dürtüsellik ve FOMO değişkenlerinin birlikte inceledikleri çalışmalarında kapsamında FOMO ve Dürtüsellik arasında pozitif yönde anlamlı düzeyde korelasyonun olduğunu belirlemişlerdir. Alan yazında sınırlı verilerin olması sebebiyle araştırmada aracı değişken olan FOMO' nun ilişkili olarak çalışıldığı yapılar incelendiğinde Oberst ve diğerlerine (2017) göre psikolojik ihtiyaçları yeterli şekilde karşılanmayan, depresyon ve anksiyete oranları yüksek bireylerde Sosyal medya kullanımına paralel olarak FOMO oranları yükselmektedir. FOMO bireylerin dikkat dağınıklı̆̆ı, anksiyete ve depresif davranışlara eğilimli olmalarına neden olmaktadır (Baker, Krieger ve LeRoy, 2016; Elhai ve diğ., 2018). FOMO'nun duygusal ve davranışsal motivasyona etkisinin incelendiği çalışma kapsamında FOMO'nun duygusal ve davranışsal motivasyonu olumsuz yönde etkilediği belirlenmiştir (Przybylski ve diğ., 2013). Dürtüselliğin de bireylerin motivasyonları üzerindeki olumsuz etkisi ve derpresyon, anksiyete gibi problemlerle karakterize olması bağlamında (Evenden 1999; Chamberlain ve Sahakian 2007; Helms ve diğ., 2008) 
düşünüldügünnde çalışma sonucunda FOMO ve Dürtüsellik arasında belirlenen pozitif korelasyonun alan yazın sonuçlarını desteklediği söylenebilir.

Riordan ve diğerleri (2015) FOMO yaşayan bireylerin akol kullanımı sırasında diğer bireylere göre daha fazla alkol tükettiği ve yoğun alkol tüketiminin olası olumsuz sonuçlarıyla daha fazla karşılaştıklarını belirtmektedirler. Yine dürtüsellik ile bağımlılık arasındaki pozitif ve anlamlı yönde ilişkilerin olduğu düşünüldüğünde (Meda ve diğg., 2009; Hamilton ve ark., 2015) davranışsal bağımlılık kategorisinde değerlendirilen sosyal medya bağımlılığı ile dürtüsellik arasında anlamlı ilişkilerin olduğu (Kim ve diğ., 2014; Mazhari, 2012; Ko, Yen, Yen, Chen, Chen, 2012; Dalbudak, Evren, Topçu, Aldemir, Coşkun, Bozkurt, Evren ve Canbal, 2013) ve FOMO ile Sosyal medya bağımlılığı arasında anlamlı düzeyde ve pozitif yönde korelasyonların olması (Wang, Zhang, Chen ve Zeng, 2018)bağlamında düşünüldüğünde araştırma sonuçlarından edinilen FOMO ve Dürtüsellik arasındaki pozitif yönde anlamlı düzeyde korelasyonun beklenilir bir sonuç olduğu söylenebilir. Diğer bir ifadeyle Dürtüsellik düzeyi yüksek bireylerin FOMO yaşaması oldukça beklenilebilir bir sonuçtur.

Araştırmanın bir diğer bulgu FOMO ve Sosyal Medya Aşerme (SMA) değişkenleri arasında anlamlı düzeyde pozitif ilişkiler olduğudur. SMA ve FOMO'nun birlikte incelendiği herhangi bir çalışmaya rastlanılmamıştır. Dolayısıyla araştırma sonuçlarının direkt olarak karşılaştırılabileceği herhangi bir veri birikimine rastlanılmamıştır. Ancak gerek FOMO'nun gerekse SMA ile ilgili yapılan çalışmaların incelenmesi neticesiyle her iki değişkenin etiyolojisi hakkında fikirler edinilmiştir. Bu bağlamda yapılan alan yazın incelemeleri neticesiyle FOMO'nun Sosyal medya bağımlılığıyla pozitif korelasyonlar sergilemesi (Beyens, Frison ve Eggermont, 2016 ; Oberst ve diğ., 2017) ve FOMO'nun sosyal medyanın yoğun bir şekilde kullanılmasına neden olduğunun belirtildiği (Turel ve Bechara, 2016) araştırma sonuçlarına ulaşılmıştır.

SMA, ilgili durum veya maddeye olan fizyolojik bağımlılığın son bulmasından sonra ilgili bağımlılık nesnesinin veya durumunun yeniden deneyimlenmesi dürtüsü olarak ele alınmaktadır (Pattij ve De Vries, 2013; Shaham ve diğ., 2000). Dolayısıyla SMA, Sosyal Medya'ya olan bağımlılığın son bulmasından sonra ortaya çıkan Sosyal Medya'nın yeniden deneyimlenmesi dürtüsü olarak değerlendirilebilir. SMA, Sosyal Medyanın yeninden deneyimlenmesini ve FOMO'nun da Sosyal medya kullanım oranını yükseltmesi 
bağlamında düşünüldüğünde SMA ve FOMO arasında anlamlı korelasyonun olması beklenilir bir sonuç olduğu söylenebilir. Dolayısıyla araştırma kapsamında edinilen sonucun literatür sonuçlarını desteklediği söylenebilir. Diğer bir ifadeyle FOMO yaşan bireylerin SMA yaşama ihtimalleri FOMO yaşamayan bireylere göre daha yüksektir. 


\title{
EXTENDED ABSTRACT
}

\section{Mediator Effect of FOMO in the Relationship Be- tween Impulsivity and Social Media Craving}

\author{
Mustafa Ercengiz \\ A ̆gr İbrahim Çeçen University
}

It is observed that there have been remarkable increases in the use of the Internet and related technology (smartphones, mobile social media etc.) in the last quarter century. According to the results of the We are Social global technology surveys 2019 report, compared to January 2018, there was a 9\% increase in internet users in January 2019, and the number of internet users grew from 3 billion 660 million individuals to 4 billion 390 million individuals. In other words, it can be said that approximately 730 million individuals started to use the internet for the first time in a period of one year.

The prevalence of the internet and related technologies, which is rapidly progressing, brings various problem areas to the life of human beings (Darcin et al., 2016; Lopez-Fernandez, 2017) in addition to providing important facilities (internet banking, mobile banking, online shopping etc.). FOMO [Fear Of Missing Out] and Social Media Craving can be considered among the current concepts among the problems brought by the use of the internet and related technology.

Impulsivity is expressed as the repetition of behavior, even though it has quite bad consequences in terms of the result of the action performed when examined from behavioral aspect (Evenden, 1999). Impulsivity can be said to be characterized by extrovert behavior patterns such as carelessness, risk taking, excitement and pleasure seeking (Hollander \& Evers, 2001).

The concept of 'Carving', expressed as 'a strong desire' in the Oxford Dictionary, has been used as "Aşerme (Carving)" in Turkish (Şengül ve Dilbaz, 2013). In recent years, the concept of craving has been used for behavioral addiction (Grant, Potenza, Weinstein and Gorelick, 2010) and has started to be evaluated among 3 groups (brain reward system, substance reinforcing effect and craving) used in defining neurobiology of addiction (Koob and Volkow, 2010). 
Field literature reviews show that impulsivity, FOMO, and social media craving, which are research variables, may be related concepts in related articles. As a matter of fact, no study has been found in which the concepts of the research are examined as a whole. Therefore, it can be said that a literature gap has occurred, and one of the aims of the study is to fill the data gap. However, the ultimate purpose of the study is to search the answer to the question of what can be done to prevent the terrible figures in the increase of the related disorders and use of the internet and related technologies given above. The purpose of the study is provide resources for intervention methods to be developed for the treatment of technology problems by providing the formation of data accumulation in order to understand the etiology of the problems arising from the internet and related Technologies.

\section{Working group}

The participant group of the study consists of 251 individuals, 106 of whom are women and 145 of whom are enrolled at Ağrı İbrahim Çeçen University in the 2018-2019 fall semester. Appropriate sampling method was used to determine the participants. The data collection tools were implemented to students voluntarily in the classrooms where they were educated at the University.

\section{Data Collection Tools}

Barratt Impulsivity Scale Short Form (BIS-11-KF): The scale, adapted to Turkish by Tamam, Güleç and Karaman (2013), has a 15-item, 4-point Likert type. Social Media Craving Scale (SMAÖ): SMAÖ scale was developed by Savc1 and Griffiths (2019) with the change of Penn Alcohol Craving Scale (Flannery, Volpicelli and Pettinati, 1999), and it consists of 5 items and one sub-dimension.

Fear of Missing Developments in Social Environments (SGKKÖ): The validity and reliability study of the Fear of Missing Developments in Social Environments (SGKKÖ) was conducted by Gökler, Aydın, Ünal and Metintaş, (2016), and it is is a 5-point likert scale consisting of 10 items and a single subdimension. 


\section{Model of the Research}

In this study, the mediating effect of FOMO in the relationship between Impulsivity and Social Media Craving is examined.

\section{Results}

Within the scope of the study, FOMO's mediating effect is tested in the relationship between Impulsivity and Social Media Craving. The findings showed that FOMO mediated the relationship between Impulsivity and Social Media Craving. In the study, it was determined that proposed regression models based on the theoretical basis were appropriate and mediated by FOMO. According to another output of the study, Impulsivity predicts FOMO significantly. Another result of the study, there is a significant positive relationship between FOMO and Social Media Craving (SMA) variables.

\section{Discussion}

Within the scope of the study, FOMO's mediating effect is tested in the relationship between Impulsivity and Social Media Craving. The findings showed that FOMO mediated the relationship between Impulsivity and Social Media Craving. In the study, it was determined that proposed regression models based on the theoretical basis were appropriate and mediated by FOMO.

No studies were found to compare the findings obtained in the study. As a matter of fact, considering the positive correlations between impulsivity and social media addiction (Kim et al., 2014; Mazhari, 2012; Ko, Yen, Yen, Chen and Chen, 2012; Dalbudak, Evren, Topçu, Aldemir, Coşkun, Bozkurt, Evren and Canbal, 2013), social media addiction and social media craving (Turel ve Bechara, 2016), which are the variables of the study, it can be said that there may be a significant relationship between impulsivity and social media craving.

SMA is treated as the urge to re-experience the relevant addiction object or state after the end of physiological dependence on the related condition or substance (Pattij and de Vries, 2013; Shaham et al., 2000). Therefore, SMA can be regarded as the urge to re-experience social media that occurs after the end of dependence on social media. When SMA is considered in the context of the 
re-experience of Social Media and FOMO increasing the rate of Social media use, it can be said that a significant correlation between SMA and FOMO is an expected result. Therefore, it can be said that the result obtained in the research supports the results of the literature. In other words, individuals who experience FOMO are more likely to experience SMA than those who do not experience FOMO.

\section{Kaynakça / References}

Albayrak, A. S. (2005). Çoklu doğrusal bağlantı halinde en küçük kareler tekniğinin alternatifi yanlı tahmin teknikleri ve bir uygulama. Zonguldak Karaelmas Üniversitesi Sosyal Bilimler Dergisi, 1(1), 105-126.

Arısoy, Ö. (2009). İnternet bağimlılığı ve tedavisi. Psikiyatride Güncel Yaklaşimlar, 1, 55-67.

Baker, Z. G., Krieger, H., ve LeRoy, A. S. (2016). Fear of missing out: Relationships with depression, mindfulness, and physical symptoms. Translational Issues in Psychological Science, 2(3), 275.

Barlas, L. (2018). Opioid bağımlılığı tedavisinde olan bir grup hastada öz bildirim ile davranışsal dürtüsellik değerlerinin karşılaştırılması. Hacettepe Üniversitesi Sosyal Bilimler Enstitüsü Psikoloji Anabilim Dalı Klinik Psikoloji Bilim Dalı. Ankara.

Barratt, E. S., ve Patton, J. H. (1983). Biological basis of sensation- seeking, impulsivity and anxiety: impulsivity: cognitive, behavioral, and psychophysiological correlates. (Ed. M. Zuckerman), Lawrence Erlbaum Associates: Hillsdale NJ. 77-116.

Beyens, I., Frison, E., ve Eggermont, S. (2016). I don't want to miss a thing: adolescents' fear of missing out and its relationship to adolescents' social needs, facebook use, and facebook related stress. Computers in Human Behavior, 64, 1-8.

Büyüköztürk, Ş. (2010). Sosyal bilimler için veri analizi el kitabı. Ankara: Pegem. Büyüköztürk, Ş., Kılıç Çakmak E., Akgün, Ö. E., Karadeniz, Ş. ve Demirel, F. (2008). Bilimsel araştırma yöntemleri (Genişletilmiş İkinci Baskı). Ankara: Pegem Yayınları.

Caselli, G., Nikcevic, A., Fiore, F., Mezzaluna, C., ve Spada, M. M. (2012). Desire thinking across the continuum of nicotine dependence. Addiction Research and Theory, 20(5), 382-388. http://dx.doi.org/10.3109/16066359.2011.644842 
Caselli, G., ve Spada, M. M. (2010). Metacognitions in desire thinking: A preliminary investigation. Behavioural and Cognitive Psychotherapy, 38(5), 629-637. http://dx.doi.org/ 10.1017/S1352465810000317.

Caselli, G., ve Spada, M. M. (2011). The desire thinking questionnaire: Development and psychometric properties. Addictive Behaviors, 36(11), 1061-1067. http://dx.doi.org/ 10.1016/j.addbeh.2011.06.013.

Chamberlain, S. R., ve Sahakian, B. J. (2007). The neuropsychiatry of impulsivity. Curr Opin Psychiatry, 20, 255-261.

Coşkun, S., ve Karayağız-Muşlu, G. (2019). Investigation of problematic mobile phones use and fear of missing out (FoMO) Level in adolescents. Community Ment Health J 55(6),1004-14. doi: 10.1007/s10597-01900422-8.

Çınar, Ç. Y., ve Mutlu, E. (2019). İnternet bağımlılığının benlik saygısı, dikkat, gelişmeleri kaçırma korkusu, yaşam doyumu ve kişilik özellikleri ile ilişkisi. Bağımlılık Dergisi, 20(3), 133-142.

Çokluk, Ö., Şekercioğlu, G., ve Büyüköztürk, Ş. (2012). Sosyal bilimler için çok değiş̧kenli istatistik: spss ve lisrel uygulamaları. Ankara: Pegem.

Dalbudak, E., Evren, C., Topçu, M., Aldemir, S., Coşkun, K. S., Bozkurt, M., Evren, B., ve Canbal, M. (2013). Relationship of internet addiction with impulsivity and severity of psychopathology among Turkish university students. Psychiatry Research, 210, 1086-1091.

Darcin, A. E., Kose, S., Noyan, C. O., Nurmedov, S., Yilmaz, O. ve Dilbaz, N. (2015). Smartphone addiction in relation with social anxiety and loneliness. Behaviour \& Information Technology, 35(7) http://dx.doi.org/10.1080/0144929X.2016.1158319.

David, M. E., Roberts, J. A., ve Christenson, B. (2017). Too much of a good thing: Investigating the association between actual smartphone use and individual well-being. International Journal of Human-Computer Interaction, 34(3), 265-275.

Dong, G., Wang, L., Du, X., ve Potenza, M. N. (2017). Gaming increases craving to gaming-related stimuli in individuals with internet gaming disorder. Biological Psychiatry: Cognitive Neuroscience and Neuroimaging, 2(5), 404-412. https://doi.org/10.1016/j.bpsc.2017.01.002.

Dossey, L. (2014). FOMO, digital dementia, and our dangerous experiment. Explore, 10(2), 69-73. 
Elhai, J. D., Levine, J. C., Alghraibeh, A. M., ve Alafnan, A. A., Aldraiweesh, A. A., ve Hall, B. J. (2018). Fear of missing out: Testing relationships with negative affectivity, online social engagement, and problematic smartphone use. Comput. Hum. Behav.89, 289-298.

Evenden, J. (1999). Impulsivity: a discussion of clinical and experimental findings. Journal of Psychopharmacology, 13(2), 180-192.

Gagne, M., ve Deci, E. L. (2005). Self-determination theory ' and work motivation. Journal of Organizational Behavior, 26(4) 331-362.

Gil, F., Chamarro, A. ve Oberst, U. (2015). Addiction to online social networks: a question of "fear of missing out ?. 2nd International Conference on Behavioral Addictions March 16-18, 2015. Budapest, Hungary. Journal of Behavioral Addictions, 4(1), 1-66.

Gökler, M. E., Aydin, R., Ünal, E., ve Metintaş, S. (2016). Sosyal ortamlarda gelişmeleri kaçırma korkusu Ölçeğinin Türkçe sürümünün geçerlilik ve güvenilirliğinin değerlendirilmesi. Anatolian Journal of Psychiatry/Anadolu Psikiyatri Dergisi, 17(Ek.1), 52-59.

Grant, J. E., Potenza, M. N., Weinstein, A., ve Gorelick, D. A. (2010). Introduction to behavioral addictions. The American Journal of Drug and Alcohol Abuse, 36(5), 233-241. http://dx.doi.org/10.3109/00952990.2010.491884.

Griffiths, M. D., Kuss, D. J., ve Demetrovics, Z. (2014). Social networking addiction: an overview of preliminary findings. In $\mathrm{K}$. Rosenberg ve L. Feder (Eds.). Behavioral addictions: Criteria, evidence and treatment (119141). New York, N.Y: Elsevier.

Hamilton, K. R., Mitchell, M. R., Wing, V. C., Balodis, I. M., Bickel, W. K., Filmore, M., Lane, S. D., ..., Moeller, F. G. (2015). Choice impulsivity: Definitions, measurement issues, and clinical implications. Personality Disorders: Theory, Research, and Treatment. 6(2), 182-198.

Helms, C. M., Gubner, N. R., Wilhelm, C. J., Mitchell, S. H., ve Grandy, D. K. (2008). D4 receptor deficiency in mice has limited effects on impulsivity and novelty seeking. Pharmacol Biochem Behav, 90, 387-393.

Hollander, E., ve Evers, M. (2001). New developments in impulsivity. The Lancet, 358(9286), 949-950.

Holt-Lunstad, J., Smith, T. B., ve Layton, J. B. (2010). Social relationships and mortality risk: A meta-analytic review. PLoS Medicine, 7(7), e1000316. doi: 10.137/journal.pmed.1000316. 
Hormes, J. M., Kearns, B., ve Timko, C. A. (2014). Craving Facebook? Behavioral addiction to online social networking and its association with emotion regulation deficits. Addiction, 109, 2079-2208. https://doi.org/10.1111/add.12713

Horzum, T. I. (2015). Facebook ve beğenilme güdüsü. International Journal of Social Sciences and Education Research, 1(4), 1473-1486.

Hüseyin, G., Lut, T., Medine, Y. G., Musa, T., Gonca K., Meliha Z., ve Matthew, S. S. (2008). Psychometric properties of the Turkish Version of the Barratt Impulsiveness Scale-11. Bulletin of Clinical Psychopharmachology, 18(4), 251-258.

Kim, D., Lee, Y., Lee, J., Nam, J. K., ve Chung, Y. (2014). Development of Korean smartphone addiction proneness scale for youth. PLoS ONE, 9(5). http://doi.org/10.1371/journal.pone.0097920.

Ko, C. H., Yen, J. Y., Yen, C. F., Chen, C. S., ve Chen, C. C. (2012). The association between Internet addiction and psychiatric disorder: A review of the literature. European Psychiatry, 27, 1-8.

Koob, G. F. ve Volkow, N. D. (2010). Neurocircuitry of Addiction. Neuropsychopharmacology Reviews, 35, 217-238.

Kuss, D. J., ve Griffiths, M. D. (2011). Addiction to social networks on the internet: A literature review of empirical research. International Journal of Environmental and Public Health, 8, 3528-3552.

Lopez-Fernandez O. (2017). Short version of the Smartphone Addiction Scale adapted to Spanish and French: Towards a cross-cultural research in problematic mobile phone use. Addict Behavior, 64, 275-280.

Mazhari, S. (2012). Association between problematic internet use and impulse control disorders among rranian university students. Cyber Psychology, Behavior and Social Networking, 15, 270-273.

Meda, S. A., Stevens, M. C., Potenza, M. N., Pittman, B., Gueorguieva, R., Andrews, M. M., Thomas, A.D., ..., Pearlson, G. D. (2009). Investigating the behavioral and self-report constructs of impulsivity domains using principal component analysis. Behavioral Pharmacology, 20, 390-399.

Moeller, G., Barratt, E., Dougherty, D., Schmitz, M., ve Swann, A. (2001). Psychiatric aspects of impulsivity. Am J Psychiatry, 158,1783-1793.

Oberst, U., Wegmann, E., Stodt, B., Brand, M., ve Chamarro, A. (2017). Negative consequences from heavy social networking in adolescents: The mediating role of fear of missing out. Journal of Adolescence, 55, 51-60. https://doi.org/10.1016/j.adolescence.2016.12.008. 
Pattij, T., ve De Vries, T.J. (2013). The role of impulsivity in relapse vulnerability. Current Opinion in Neurobiology, 23, 4, 700-705.

Przybylski, A. K., Murayama, K., DeHaan, C. R. ve Gladwell, V. (2013). Motivational, emotional, and behavioral correlates of fear of missing out. Computers in Human Behavior, 29, 1841-1848.

Riordan, B. C. Flett, J. A. M., Hunter, J. A. Scarf, D. ve Conner, T. S. (2015). Fear of missing out (FoMO): the relationship between FoMO, alcohol use, and alcohol-related consequences in college students. Annals of Neuroscience and Psychology, 2, 7.

Ryan, R. M., ve Deci, E. L. (2000). Self-determination theory and the facilitation ofintrinsic motivation, social development, and well-being. American Psychologist,55,68-78.

Savci, M. ve Aysan, F. (2017). "Technological addictions and social connectedness: predictor effect of internet addiction, social media addiction, digital game addiction and smartphone addiction on social connectedness", Düşünen Adam the Journal of Psychiatry and Neurological Sciences, 30(3), 202-216.

Savci, M., ve Griffiths, M. D. (2019). The development of the Turkish Social Media Craving Scale (SMCS): A validation study. International Journal of Mental Health and Addiction. doi:10.1007/s11469-019-00062-9

Shaham, Y., Erb, S., ve Stewart, J. (2000). Stress-induced relapse to heroin and cocaine seeking in rats: a review. Brain Research Reviews, 33(1), 13-33.

Swann, A. C., Moeller, F. G., Steinberg, J. L., Schneider, L., Barratt, E. S., ve Dougherty, D. M. (2007). Manic symptoms and impulsivity during bipolar depressive episodes. Bipolar Disord, 9(3), 206-12.

Şengül, C., ve Dilbaz, N. (2013). Neurobiology, Genetics and Treatment of Alcohol Craving. Düşünen Adam the Journal of Psychiatry and Neurological Sciences. 26, 381-387 doi: 10.5350/DAJPN2013260408.

Tamam, L., Güleç, H., ve Karataş, G. (2013). Barratt dürtüsellik ölçeği kısa formu (BIS-11-KF) Türkçe uyarlama çalışması. Nöropsikiyatri Arşivi, 50,130-134.

TUIK. (2019). Tarm alanlarl, http://tuik.gov.tr/PreTablo.do?alt id=1001 adresinden erişilmiştir.

Turel, O., ve Bechara, A. (2016). A triadic reflective-impulsive-interoceptive awareness model of general and impulsive information system use: behavioral tests of neuro-cognitive theory. Frontiers in Psychology, 7, 1-11. https://doi.org/10.3389/fpsyg.2016.00601. 
Vega, L. E. S., Muñoz, A. M. G., ve García L. F. (2019). Adolescents problematic mobile phone use, Fear of Missing Out and family communication / Uso problemático del móvil, fobia a sentirse excluido y comunicación familiar de los adolescentes. Comunicar, 27(59), 39-47.

Wang, G., Zhang, W., Chen, Q., ve Zeng, R. (2018). How is negative affect associated with life satisfaction? The moderating role of online selfdisclosure in China's context. Personality and Individual Differences, 135, 60-66.

Wegmann, E., Stodt, B., ve Brand, M. (2015). Addictive use of social networking sites can be explained by the interaction of internet use expectancies, internet literacy, and psychopathological symptoms. Journal of Behavioral Addictions, 4(3), 155-162. https://doi.org/10.1556/2006.4.2015.021.

Wilson, K., Fornasier, S., ve White, K. M. (2010). Psychological predictors of young adults' use of social networking sites. Cyberpsychology, Behavior and Social Networking, 13, 173-177.

Yazıcı, K., ve Yazıcı, A.E. (2010). Dürtüselliğin nöroanatomik ve nörokimyasal temelleri. Psikiyatride Güncel Yaklaşımlar, 2(2), 254-280.

\section{Kaynakça Bilgisi / Citation Information}

Ercengiz, M. (2020). Dürtüsellik ile sosyal medya aşerme arasındaki ilişkide FOMO'nun aracılık etkisi. OPUS-Uluslararası Toplum Araştırmaları Dergisi, 15(22), 854-877. DOI: 10.26466/opus.648795 